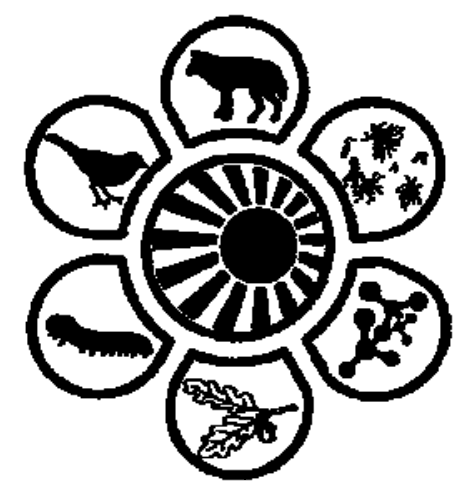

Вісник Дніпропетровського університету. Біологія, екологія.

Vìsnik Dnìpropetrovs'kogo unìversitetu. Seriâ Bìologiâ, ekologiâ

Visnyk of Dnipropetrovsk University. Biology, ecology.

Vìsn. Dnìpropetr. Unìv. Ser. Bìol. Ekol. 2015. 23(2), 91-99.

doi: $10.15421 / 011513$

ISSN 2310-0842 print

ISSN 2312-301X online

www.ecology.dp.ua

УДК 598.115.31 (477)

\title{
Распространение узорчатого полоза Elaphe dione (Reptilia, Colubridae) в Украине: исторический аспект и современное состояние
}

\author{
А.И. Тупиков ${ }^{1}$, А.И. Зиненко ${ }^{2}$ \\ ${ }^{1}$ Национальный природный парк “Двуречанский”, Двуречное, Украина \\ ${ }^{2}$ Музей природы Харьковского национального университета им. В.Н. Каразина, Харьков, Украина
}

\begin{abstract}
Узорчатый полоз - один из наименее изученных полозов фауны Украины. Согласно данным о современных находках, территория Восточной Украины является западным пределом его распространения. На территории страны включен в Красную книгу и имеет статус исчезающего вида. В Донецкой и Луганской областях вид широко распространен и довольно обычен. В то же время в литературе существуют указания о находках этого вида за пределами Восточной Украины - в Крыму и в Одесской области, сделанные в XIX - начале XX века. До настоящего времени все они остаются неподтвержденными. В результате критического анализа литературных источников и музейных коллекций сделан вывод, что, вероятнее всего, указания на обитание этого вида за пределами современного ареала связаны с ошибкой видовой идентификации или неверным этикетированием. Приводится подробное обсуждение четырех известных спорных находок с территории Южной Украины. Литературные сведения и музейные данные об узорчатом полозе обобщены и дополнены результатами собственных полевых исследований. Приводится кадастр всех известных находок вида в Украине.
\end{abstract}

Ключевые слова: Elaphe dione; Крым; Одесса; ошибка идентификации; распространение; кадастр; спорные находки

\section{Distribution of the Dione snake Elaphe dione (Reptilia, Colubridae) in Ukraine: Historical aspect and the current state}

\author{
A.I. Tupikov", O.I. Zinenko ${ }^{2}$ \\ ${ }^{I}$ National Nature Park "Dvorichanskiy", Dvorichna, Ukraine \\ ${ }^{2}$ Museum of Nature at V.N. Karazin Kharkiv National University, Kharkiv, Ukraine
}

The Dione snake is one of least known species of racers in the fauna of Ukraine. According to the current data, the territory of Eastern Ukraine is the western boundary of the species' distribution. The Dione snake is listed in the Red book of Ukraine and has a status of endangered taxon. This species is locally distributed and comparatively common in Donetsk and Lugansk regions. At the same time, in the historical references of the XIX - beginning of the XX century the data about findings of the species beyond the Eastern Ukraine, in the Crimea and Odessa region, is present. Despite the fact that these cases are well known to old zoologists, they remain neither confirmed, nor properly rejected as erroneous ones. We have carried out the critical analysis of museum specimens and these literature sources and drawn the conclusion that the records of the species' localities beyond the modern range were the result of misidentifications or mislabellings. In this article we describe in detail four disputable findings in the Southern Ukraine. Besides, we summarize literature and museum data about the Dione snake and complement it with our own field observations in the comprehensive list of localities of this species in Ukraine. The annotated cadastre of localities of Dione snake in Ukraine is provided.

Keywords: Elaphe dione; Crimea; Odessa; mislabelling; misidentification; distribution; cadastre

Национальный природный парк “Двуречанский”, ул. Привокзальная, 51, пос. Двуречное, 62701, Украина National Nature Park "Dvorichanskiy”, Privokzalna Str., 51, Dvorichna, 62701, Ukraine

Tel.: +38-050-839-04-51.E-mail: a.i.tupikov@gmail.com

Музей природы Харьковского начионального университета им. В.Н. Каразина, ул. Тринклера, 8, Харьков, 61058, Украина Museum of Nature at V.N. Karazin Kharkiv National University, Trinkler Str., 8, Kharkiv, 61058, Ukraine

Tel.: +38-066-191-08-67. E-mail: zinenkoa@yahoo.com

Visn. Dnipropetr. Univ. Ser. Biol. Ekol. 2015. 23(2) 


\section{Введение}

Узорчатый полоз Elaphe dione (Pallas, 1773) - один из наиболее «широкоареальных» представителей рода Elaphe, живущих на территории Евразии. Высокая экологическая пластичность этого вида позволила ему занимать разнообразные биотопы: от полупустынь и пустынь Центральной Азии до влажных пойменных лесов Дальнего Востока, от Приморья до Восточной Европы (Nikol'skij, 1916; Shherbak, 1966; Bannikov et al., 1977; Ananjeva et al., 1998). Западным пределом распространения узорчатого полоза считается Восточная Украина, где он обитает, преимущественно, в Донецкой и Луганской областях.

На данный момент его распространение на территории Украины недостаточно изучено. С середины XIX и до начала XX века в литературе упоминались единичные находки этого вида на территории западной и южной частей современной Украины: в Крыму и в Одесской области (Kessler, 1860; Strauch, 1873, Nikol'skij, 1905, 1916; Duméril and Bibron, 1854). Однако позднее вид здесь не находили, а правильность определения экземпляров ставилась под сомнение более поздними авторами (Cemsh, 1939; Pashhenko, 1954; Tarashchuk, 1956, 1959; Bannikov et al., 1977; Ananjeva et al., 1998; Akimov, 2009), хотя бесспорным признавалось присутствие вида в Луганской и Донецкой областях. Многочисленные достоверные данные о находках вида стали активно накапливаться начиная с 1990-х годов и были только частично обобщены в видовом очерке для Красной книги Украины (Akimov, 2009), куда узорчатый полоз был включен со статусом «исчезающий». Эта змея также внесена в ряд региональных охранных списков: Донецкой, Луганской, Харьковской (известен по единственной находке в 2007 г.) и Днепропетровской областей (считается исчезнувшим, Bulakhov et al., 2007; Pakhomov et al., 2011).

В этой работе мы описываем историю изучения узорчатого полоза, его распространение в административных границах Украины, а также приводим кадастр находок вида, составленный по литературным источникам, музейным коллекциям и собственным наблюдениям.

\section{Материал и методы исследований}

Проанализированы литературные источники, каталоги и коллекции музеев (Зоологический музей ННПМ НАН Украины, Киев, Украина; Музей природы Харьковского национального университета им. В.Н. Каразина, Харьков, Украина; Музей естественной истории, Париж, Франция; Музей ЗИН РАН, Санкт-Петербург, РФ). Собственные данные получены во время полевых сезонов 2003-2015 гг. на территории Донецкой, Луганской и южной части Харьковской областей. Координаты находок определяли при помощи GPS-навигатора или за место находки принимали ближайший указанный в источнике (литературе, музейной этикетке) географический пункт (населенный пункт, объект, обозначенный на топографической карте или на спутниковом снимке), координаты центра которого определяли при помощи Google Maps, Google Earth и Ozzi Explorer. Карта распространения (рис. 3) генерирована в программе Quantum GIS.

\section{Результаты и их обсуждение}

База данных находок узорчатого полоза в Украине состоит из 66 записей. В общей сложности присутствие узорчатого полоза подтверждено литературными источниками, коллекциями или непосредственными наблюдениями в 56 локалитетах. Пять находок приходится на XIX век; из оставшихся - 63\% на последние два десятилетия. Из всех указанных находок 88\% сделаны на территории Луганской и Донецкой областей, в степной зоне Украины.

Одно из первых и, пожалуй, самое интересное и спорное упоминание о находке узорчатого полоза на территории Украины приводится в ряде старых источников со ссылкой на хранящийся в Парижском музее экземпляр, присланный Нордманом в 1850 г. из Одессы (Duméril and Bibron, 1854; Kessler, 1860; Strauch, 1873; Nikol'skij, 1891, 1905, 1916; рис. 1).

Ряд более поздних сомнительных находок этого вида до 1920-х гг. сделан в южных украинских областях (Kessler, 1860; Strauch, 1873; Nikol'skij, 1891, 1905, 1916; Sukhow, 1927). Последним, завершающим череду спорных находок, является экземпляр из окрестностей дер. Кигач Перекопского уезда (ныне с. Новопавловка Красноперекопского района; рис. 2), в настоящее время хранящийся в Музее ЗИН РАН (№13 659 (№ 259-916) и датированный 27.06.1916 г.

Все перечисленные указания находок узорчатого полоза из южной части материковой Украины и Крыма неоднократно подвергались сомнениям. Основным, часто встречающимся аргументом против принятия этих находок была путаница в идентификации сарматского (четырехполосого) и узорчатого полозов в то время. Так, в своей монографии «Пресмыкающиеся и земноводные Российской Империи» А.М. Никольский (Nikol'skij, 1905) объединяет четырехполосого (вместе с сарматским полозом) и узорчатого полоза в один таксон Coluber dione Pall., мотивируя это тем, что «нет ни одного более или менее постоянного признака, по которому можно было бы отличить $C$. quatuorlineatus от $C$. dione, равно как эти виды не отличаются суммой признаков». А.А. Браунер также писал в это же время, что узорчатый и палласов (четырехполосый) полозы «различаются только по окраске и то, не резко и притом во взрослом состоянии, поэтому они должны быть соединены в один вид Coluber quatuorlineatus» (Brauner, 1904). Исходя из этой позиции, совершенно ожидаемо то, что в своих работах, А.А. Браунер вообще не указывает узорчатого полоза для юга Украины.

Однако в своих дальнейших работах А.М. Никольский (Nikol'skij, 1916) признает видовую самостоятельность узорчатого полоза: «Описываемый вид (Elaphe quatuorlineata) в особенности в молодом возрасте походит на $E$. dione. В своей работе «Herpetologia rossica» я даже соединил их... Однако многочисленные экземпляры той и другой формы, полученные главным образом из Кавказа, убедили меня в том, что я сделал тогда ошибку. E. dione и E. quautorlineata, несомненно, два совершенно различных вида». Здесь же он также отмечает, что данные об обитании узорчатого полоза в Крыму и Одессе недостоверны, т. к. не были подтверждены более поздними находками и музейными экземплярами. Путаница с видовой идентификацией продолжается и позже, вплоть 
до второй половины XX в. Так, экземпляр, определенный как узорчатый полоз и собранный на Арабатской стрелке

(Docenko, 2003), был позже переопределен как сарматский (Палласов) полоз (Kotenko, 2010).
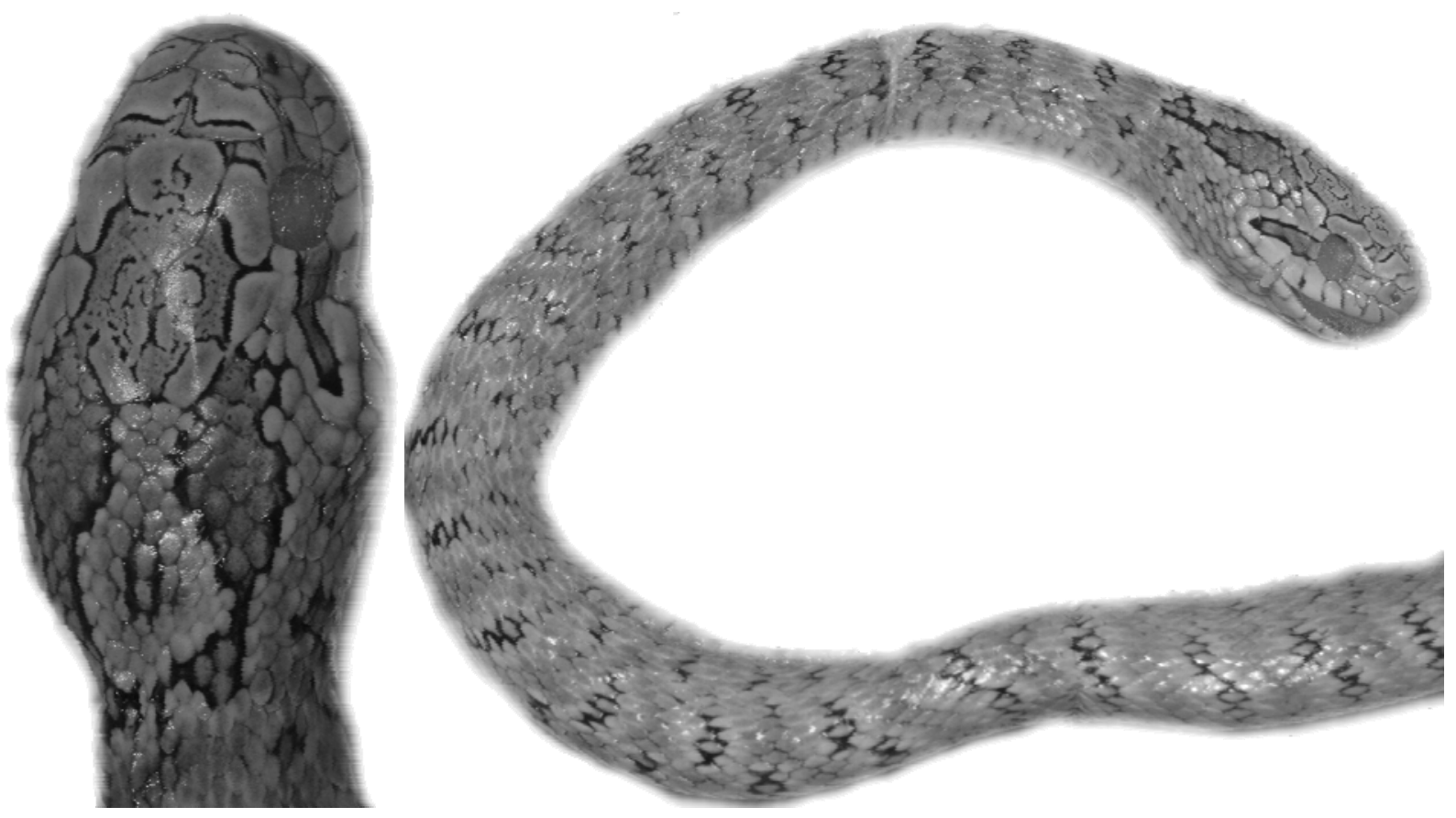

Рис. 1. Экземпляр Elaphe dione (Pallas, 1773) из окрестностей г. Одесса (1850 г.). Фото Ivan Ineich


Рис. 2. Экземпляр Elaphe dione (Pallas, 1773) из окр. дер. Кигач Перекопского уезда (1916 г.). Фото И. Доронина

Далее мы остановимся на каждом из четырех известных спорных экземпляров $E$. dione, найденных на территории Украины за пределами современного ареала.

1. Экземпляр из окрестностей г. Одесса. Хранится в коллекции Музея естественной истории Парижа (Франция). Этикеточные данные: «MNHN-RA-0.3365, Odessa, Leg. Nordmann». Исходя из литературных источников, этот экземпляр передан в Париж в 1850 г. А. Нордманном
(Strauch, 1873; Nikol'skij, 1891). А.М. Никольский, поддерживая точку зрения А. Штрауха, пишет об этом экземпляре: «если это в действительности $C$. dione Pall., то экземпляр этот происходит не из окрестностей Одессы» (Nikol'skij, 1916). Опираясь на полученные фотоматериалы (рис. 1), мы подтверждаем правильность определения $E$. dione. Однако, принимая во внимание отсутствие более поздних находок этого вида в указанном регионе (Cemsh, 
1939; Terent'ev and Chernov, 1949; Pashhenko, 1954; Tarashchuk, 1956; Bannikov et al., 1977; Shherbak, 1966; Akimov, 2009; Kotenko, 2010), вслед за А.М. Никольским мы склонны считать этот факт ошибкой этикетирования.

2. Экземпляр из коллекции Симферопольской гимназии. Об этом экземпляре узорчатого полоза впервые становится известно из работы К. Кесслера «Путешествие с зоологической целью к северному побережью Черного моря и в Крым в 1858 г.», изданному в 1860 г. Стоит отметить, что в своей работе автор не предоставил никаких подробных сведений, кроме списка видов: «Зоологическая коллекция Симферопольской гимназии, составленная г. Бобровским, была уже довольно богата туземными земноводными. Из ящериц в ней находились Lacerta stirpium Daud., taurica Pall., muralis L., из ужей Coronella laevis Laur. (во многих экземплярах), Tropidonotus natrix L. et hydras Pall. и Coluber dione Pall.». A.M. Никольский, обсуждая эту находку, писал следующее: «По словам К.Ф. Кесслера, в коллекции Симферопольской гимназии находится Elaphis dione Pall., но, по мнению А. Штрауха, это без сомнения есть молодой E. sauromates Pall.» (Nikol'skij, 1891). Учитывая существующую и многократно обсуждаемую в то время проблему в установлении точной видовой идентификации родственных видов полозов (Nikol'skij, 1891, 1905, 1916; Strauch, 1873; Brauner, 1904; Sukhow, 1927; Tarashchuk, 1956), указанную находку нельзя принимать за достоверное подтверждение о нахождении вида в Крыму. Кроме этого, все последующие указания других авторов на эту находку являются лишь ссылкой на работу К. Кесслера.

3. Экземпляр из коллекции зоологического музея Московского университета. Одно из первых указаний на этот экземпляр принадлежит А.М. Никольскому. В своей работе «Позвоночные животные Крыма» он указывает следующее: «Г. Кулагин в списке гадов музея Московского университета приводит экземпляр этой змеи [узорчатого полоза - прим. авт.] за № 331, с обозначением «из Южной России. Крым». Экземпляр получен в 1878 г. от общества Любителей Естествознания. Однако на основании этого показания я не решаюсь включать названный вид в число крымских животных» (Nikol'skij, 1891). Такого же мнения придерживается и Н.Н. Щербак (Shherbak, 1966), также связывая это указание вида для Крыма с ошибками определения.

4. Экземпляр из окр. дер. Кигач, Красноперекопского уезда. Ныне этот экземпляр хранится в Зоологическом институте Российской Академии наук, г. СанктПетербург (№ 13659 (№ 259-916) 27.06.1916 г. Leg. Рашковский. Det. Чернов, 1934). Как и в случае с «одесским» экземпляром, опираясь на полученные фотоматериалы (рис. 2), мы не сомневаемся в правильности определения вида. Опираясь на эту находку, в своих последующих работах С.А. Чернов указывает узорчатого полоза для района между Крымом и континентальной Украиной (Terent'ev and Chernov, 1936, 1949, 1965). Эта же находка обозначена (со смещением к северу) в авторитетном определителе А.В. Банникова с соавторами (Bannikov et al., 1977). Наиболее вероятным ее объяснением остается ошибка этикетирования. По результатам многолетних исследований, проводимых другими авторами, этот вид на указанных территориях не был обна- ружен (Shherbak, 1966; Karmyshev, 2002; Kotenko and Kukushkin, 2003; Kukushkin and Kotenko, 2003; Kotenko, 2010). Вероятность того, что вид действительно присутствовал в Крыму и исчез в историческое время (Shherbak, 1966), на наш взгляд, крайне низка.

Позднее, на протяжении всего XX века, вид не привлекал особенного внимания герпетологов. О достоверном обитании узорчатого полоза на территории Восточной Украины становится известно в 1927 г. из публикации Г.Ф. Сухова. В ней же он упоминает и экземпляр, добытый в 1887 г. Лукашевым с территории Екатеринославской губернии (ныне центральная часть Донецкой обл., часть Луганской, Днепропетровской и Запорожской областей) и хранившийся в Зоологическом музее НАН Украины (Sukhow, 1927). Эти находки располагались в границах известного нам на сегодняшний момент ареала узорчатого полоза.

Стоит отметить, что в своих работах и Г.Ф. Сухов, и В.В. Таращук принимают правильность определения полозов, добытых с территории Крыма и окрестностей Одессы, а также их вероятное там обитание. В.В. Таращук (Tarashchuk, 1956) говорит, что «маловероятно, чтобы такие знатоки фауны, как А. Нордман, К.Ф. Кесслер и Н.М. Кулагин, могли совершить подобную ошибку, потому что узорчатый и четырехполосый полозы мало схожи и очень легко отличаются». Однако И.А. Цемш, изучавший географическое распространение амфибий и рептилий на территории Украины, в своей работе, ссылаясь на работу Г.Ф. Сухова 1927 г., указывает лишь одну достоверную находку узорчатого полоза с территории Екатеринославской губернии (Cemsh, 1939).

Все последующие находки полоза были приурочены исключительно к территориям Восточной Украины (Донецкая и Луганская обл.), и нет ни одного случая поимки змеи с территории Правобережной Украины или Крыма (Sukhow, 1927; Cemsh, 1939; Terent'ev and Chernov, 1936, 1949, 1965; Pashhenko, 1954; Tarashchuk, 1956, 1959; Shherbak, 1966; Akimov, 2009). Наконец, уже в конце 1990-х и начале 2000-х гг. вышел ряд работ, в которых узорчатый полоз также приводится только для Восточной Украины, а количество точек находок начинает превышать десятки (Reva et al., 1989; Vlasenko and Taranenko, 2002, 2003; Kotenko and Kondratenko, 2005; Vedmederja et al., 2007; Kurjachij and Tupikov, 2008; Kotenko, 2008; Zaika, 2008; Zagorodnjuk and Zaïka, 2009).

Ниже мы приводим карту распространения узорчатого полоза в Украине (рис. 3). В таблице перечислены все известные находки узорчатого полоза на территории Украины в период с 1850 по 2015 год, где графа «№» соответствует номеру точки на карте.

Палеонтологические данные о распространении узорчатого полоза на территории современной Украины в геологическом прошлом крайне скудны. Первое упоминание о найденных останках узорчатого полоза известно из публикации об «Ископаемых верхнечетвертичных грызунах предгорного Крыма» (Gromov, 1961). Остатки были обнаруженны в отложениях раннего и среднего голоцена в пещерах Сюрень II и Змеиный навес (окрестности с. Танковое) и Алимовский навес (окрестности с. Баштановка) в Бахчисарайском р-не Крыма. Однако, по мнению Т.И. Котенко (Kotenko, 2010), в правильности определения этих остатков есть большие со- 
мнения и, скорее всего, они принадлежат не $E$. dione, а родственному E. sauromates. Кроме этого, известна еще одна находка Elaphe aff. dione (aff. - сокращение от слова affinis - родственный) в плиоценовом местонахожде- нии Котловина в Одесской области (Ratnikov, 2009). Однако качество определения и в этом случае не позволяет с уверенностью говорить о присутствии узорчатого полоза в окрестностях Одессы в плиоценовый период.

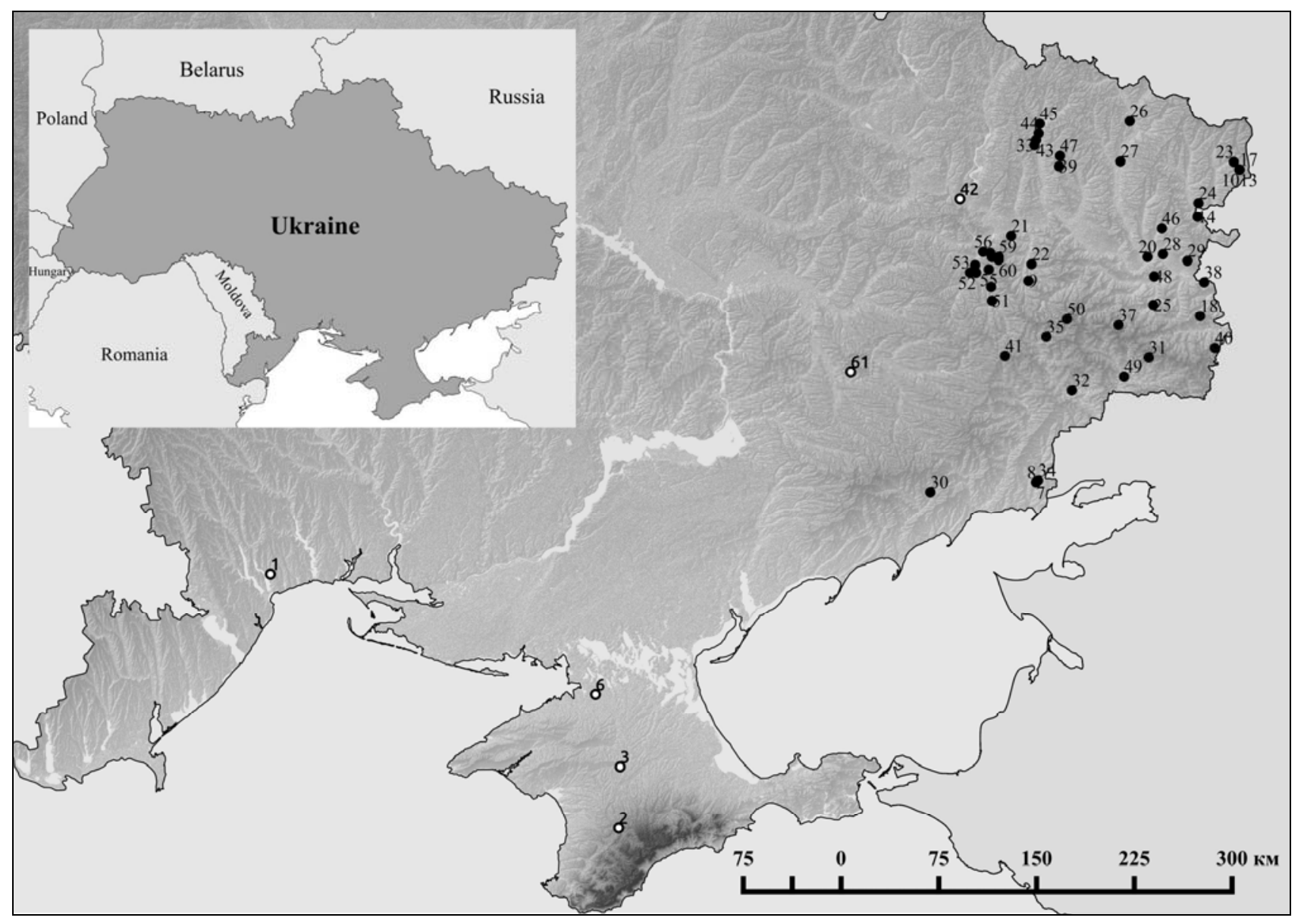

Рис. 3. Распространение узорчатого полоза в Украине:

- - места находок Elaphe dione (по литературным источникам и собственным данным); o - спорные места находок $E$. dione

Кадастр находок узорчатого полоза на территории Украины в 1850-2015 гг.

\begin{tabular}{|c|c|c|c|c|}
\hline № & Дата & Локалитет & Источник & Дополнительная информация \\
\hline 1 & 2 & 3 & 4 & 5 \\
\hline 1 & 1850 & Окрестности г. Одесса & Strauch, 1873; Nikol'skij, 1891 & MNHN-RA-0.3365, Odessa, Leg. Nordmann \\
\hline 2 & 1858 & Крым & $\begin{array}{l}\text { Kessler, 1860; Strauch, 1873; } \\
\text { Nikol'skij, } 1891\end{array}$ & $\begin{array}{c}\text { Музей Симферопольской гимназии. Экземпляр } \\
\text { не сохранился. В перечне поступлений в кол- } \\
\text { лекцию музея данные отсутствуют (О.В. Ку- } \\
\text { кушкин, личное сообщение) }\end{array}$ \\
\hline 3 & 1878 & Крым & Nikol'skij, 1891 & Местонахождение точно не указано \\
\hline 4 & 1887 & Екатеринославская губерния & Sukhow, 1927; Cemsh, 1939 & Местонахождение точно не указано \\
\hline 5 & 1887 & Екатеринославская губерния & Docenko, 2003 & $\begin{array}{l}\text { 3М ННПМ. Инв. № 694/2009, } 1 \text { ad., Leg. Брау- } \\
\text { нер. Местонахождение точно не указано }\end{array}$ \\
\hline 6 & $\begin{array}{r}1916 \\
27.06\end{array}$ & $\begin{array}{c}\text { Крым, Перекопский уезд, окр. } \\
\text { дер. Кигач (совр. с. Новопавловка) }\end{array}$ & - & $\begin{array}{l}\text { ЗИН РАН, №13659 (№259-916) 27.06.1916 г. } \\
\text { Leg. Рашковский. Det. Чернов, } 1934\end{array}$ \\
\hline 7 & 1935 & $\begin{array}{c}\text { «Хомутовская степь», } \\
\text { Новоазовский р-н, Донецкая обл. }\end{array}$ & $\begin{array}{l}\text { Docenko, 2003; Kotenko and } \\
\text { Kurjachyj, } 2008\end{array}$ & $\begin{array}{l}\text { 3М ННПМ, Инв. № 744/2083, } 1 \text { ad., } \\
\text { Leg. Шарлемань? }\end{array}$ \\
\hline 8 & 1938 & $\begin{array}{c}\text { «Хомутовская степь», } \\
\text { Буденовский р-н, Донецкая обл. }\end{array}$ & Pashhenko, 1954 & $\begin{array}{c}\text { По устному сообщению Шарлеманя, } \\
\text { экземпляр передан в Ин-т зоологии АН УССР }\end{array}$ \\
\hline 9 & 1941 & Окр. г. Артемовск, Донецкая обл. & Pashhenko, 1954 & Leg. И.С. Даревским. Передан в зоомузей МГУ \\
\hline 10 & 1949 & $\begin{array}{l}\text { Зап. «Стрельцовская степь», } \\
\text { Луганская обл. }\end{array}$ & Tarashchuk, 1956 & Добыт Г.В. Модиным \\
\hline 11 & 1951 & $\begin{array}{l}\text { Зап. «Стрельцовская степь», } \\
\text { Луганская обл. }\end{array}$ & Pashhenko, 1954 & $\begin{array}{c}\text { По устному сообщению Шарпило, } \\
\text { добыт им летом } 1951 \text { г. Экземпляр передан } \\
\text { в Ин-т зоологии АН УССР }\end{array}$ \\
\hline
\end{tabular}




\begin{tabular}{|c|c|c|c|c|}
\hline 1 & 2 & 3 & 4 & 5 \\
\hline 12 & 1951 & $\begin{array}{l}\text { Зап. «Стрельцовская степь», } \\
\text { Луганская обл. }\end{array}$ & Tarashchuk, 1956 & Leg. В.И. Таращук \\
\hline 13 & 1952 & $\begin{array}{c}\text { Зап. «Стрельцовская степь», } \\
\text { Луганская обл. }\end{array}$ & Pashhenko, 1954 & $\begin{array}{c}\text { Несколько экземпляров, добытых Г.В. Моди- } \\
\text { ным. Часть передана в Ин-т зоологии } \\
\text { АН УССР, } 3 \text { экз. переданы в Зоомузей КГУ }\end{array}$ \\
\hline 14 & 1956 & $\begin{array}{l}\text { Деркульская н.-и. станция, } \\
\text { Луганская обл. }\end{array}$ & $\begin{array}{l}\text { Kotenko and Kondratenko, } \\
2005\end{array}$ & - \\
\hline 15 & $\begin{array}{r}1963 \\
27.06\end{array}$ & Крым, Арабатская стрелка & Docenko, 2003 & $\begin{array}{c}\text { 3М ННПМ, Инв. №1281/3018, } 1 \text { juv. } \\
\text { Переопределен Т.И. Котенко как E. sauromates }\end{array}$ \\
\hline 16 & $\begin{array}{l}1964 \\
19.07\end{array}$ & $\begin{array}{l}\text { Зап. «Стрельцовская степь», } \\
\text { Луганская обл. }\end{array}$ & Docenko, 2003 & $\begin{array}{l}\text { 3М ННПМ, Инв. № 725/2056, } 1 \text { ad., } \\
\text { Leg. В.Г. Шарпило }\end{array}$ \\
\hline 17 & $\begin{array}{l}1974 \\
\text { VIII }\end{array}$ & $\begin{array}{l}\text { Зап. «Стрельцовская степь», } \\
\text { Луганская обл. }\end{array}$ & Vedmederja et al., 2007 & $\begin{array}{c}\text { Музей природы ХНУ, } \\
\text { Инв. №27741, } 1 \text { экз., Leg. Е.В. Астахова }\end{array}$ \\
\hline 18 & $\begin{array}{r}1976 \\
13.04\end{array}$ & $\begin{array}{c}\text { Окр. г. Суходольск, } \\
\text { Краснодонский р-н., Луганская обл. }\end{array}$ & Vedmederja et al., 2007 & $\begin{array}{c}\text { Музей природы ХНУ, } \\
\text { Инв. №29063, } 2 \text { экз., Leg. Л.И. Пеева }\end{array}$ \\
\hline 19 & $\begin{array}{r}1984 \\
14.05\end{array}$ & $\begin{array}{c}\text { Пос. Белокузьминовка, } \\
\text { Донецкая обл. }\end{array}$ & Docenko, 2003 & $\begin{array}{c}\text { 3М ННПМ, } \\
\text { Инв. № 1149/2817, ad., Leg. Т.И. Котенко }\end{array}$ \\
\hline 20 & $\begin{array}{r}1987 \\
23.09 \\
\end{array}$ & Окр. с. Счастье, Луганская обл. & Docenko, 2003 & $\begin{array}{c}\text { 3М ННПМ, } \\
\text { Инв. № 1403/3516-3517, ad., Leg. Марчук. }\end{array}$ \\
\hline 21 & $1987-1989$ & $\begin{array}{l}\text { с. Кривая Лука, Краснолиманский } \\
\text { р-н, Донецкая обл. }\end{array}$ & Reva et al., 1989 & - \\
\hline 22 & $1987-1989$ & $\begin{array}{c}\text { Окр. г. Карло-Либкнехтовск } \\
\text { (совр. г. Соледар), Донецкая обл. }\end{array}$ & Reva et al., 1989 & - \\
\hline 23 & 1990-е гг. & $\begin{array}{l}\text { Окр. с. Великоцк, } \\
\text { Луганская обл. }\end{array}$ & $\begin{array}{l}\text { Kotenko and Kondratenko, } \\
2005\end{array}$ & - \\
\hline 24 & $\begin{array}{c}1990- \\
2000 \text { гг. }\end{array}$ & $\begin{array}{l}\text { Заказник «Юницкий», } \\
\text { Луганская обл. }\end{array}$ & $\begin{array}{l}\text { Kotenko and Kondratenko, } \\
2005\end{array}$ & - \\
\hline 25 & $\begin{array}{c}1990- \\
2000 \text { гг. }\end{array}$ & Окр. с. Георгиевка, Луганская обл. & $\begin{array}{l}\text { Kotenko and Kondratenko, } \\
2005\end{array}$ & - \\
\hline 26 & $\begin{array}{c}1990- \\
2000 \text { гг. }\end{array}$ & $\begin{array}{l}\text { Окр. сс. Осиново, Рогово, } \\
\text { Тевяшево, Луганская обл. }\end{array}$ & $\begin{array}{l}\text { Kotenko and Kondratenko, } \\
2005\end{array}$ & - \\
\hline 27 & $\begin{array}{c}1990- \\
2000 \text { гг. }\end{array}$ & Окр. с. Лиман, Луганская обл. & $\begin{array}{l}\text { Kotenko and Kondratenko, } \\
2005\end{array}$ & - \\
\hline 28 & $\begin{array}{c}1990- \\
2000 \text { гг. }\end{array}$ & $\begin{array}{l}\text { «Придонцовская пойма», Луган- } \\
\text { ский прир. зап., Луганская обл. }\end{array}$ & $\begin{array}{l}\text { Kotenko and Kondratenko, } \\
2005\end{array}$ & - \\
\hline 29 & $\begin{array}{c}1990- \\
2014 \text { гг. }\end{array}$ & $\begin{array}{l}\text { Окр. сс. Чугинка, Герасимовка, Ка- } \\
\text { мышное, Ольховое, Луганская обл. }\end{array}$ & $\begin{array}{l}\text { Kotenko and Kondratenko, } \\
\text { 2005; Zagorodnjuk, } 2014\end{array}$ & - \\
\hline 30 & $\begin{array}{c}1990- \\
2000 \text { гг. }\end{array}$ & Окр. с. Федоровка, Донецкая обл. & $\begin{array}{l}\text { Kotenko and Kondratenko, } \\
2005\end{array}$ & - \\
\hline 31 & $\begin{array}{c}1990- \\
2000 \text { гг. }\end{array}$ & Окр. с. Ильинка, Донецкая обл. & $\begin{array}{l}\text { Kotenko and Kondratenko, } \\
2005\end{array}$ & - \\
\hline 32 & $\begin{array}{c}1990- \\
2000 \text { гг. }\end{array}$ & $\begin{array}{c}\text { Окр. пос. Благодатное, Донецкая } \\
\text { обл. }\end{array}$ & $\begin{array}{l}\text { Kotenko and Kondratenko, } \\
\text { 2005; L.Y. Taranenko (per- } \\
\text { sonal comment) }\end{array}$ & - \\
\hline 33 & 1998 & $\begin{array}{l}\text { Национальный природный парк } \\
\text { «Святые горы», Донецкая обл. }\end{array}$ & Reva et al., 1989 & $\begin{array}{c}\text { Окр. пос. Кривая Лука } \\
\text { (Л.И. Тараненко, личное сообщение) }\end{array}$ \\
\hline 34 & 1997,2007 & Окр. с. Сосновое, Луганская обл. & Zaika, 2008 & - \\
\hline 35 & 2000-е гг. & Окр. пос. Самсоново, Донецкая обл. & $\begin{array}{l}\text { Kotenko and Kondratenko, } \\
2005\end{array}$ & - \\
\hline 36 & 2000-е гг. & Окр. г. Енакиево, Донецкая обл. & Kotenko and Kurjachyj, 2008 & - \\
\hline 37 & 2002 & $\begin{array}{l}\text { Окр. Новодмитровки, } \\
\text { Донецкая обл. }\end{array}$ & $\begin{array}{c}\text { Kotenko and Kurjachyj, 2008; } \\
\text { our data }\end{array}$ & - \\
\hline 38 & $\begin{array}{l}2003 \\
15.09\end{array}$ & Окр. с. Петровское, Луганская обл. & Vedmederja et al., 2007 & $\begin{array}{c}\text { Музей природы ХНУ, } \\
\text { Инв. № Г-1156, А.И. Зиненко }\end{array}$ \\
\hline 39 & 2004 & $\begin{array}{c}\text { Между сс. Пархоменко и } \\
\text { Кружиловка, Луганская обл. }\end{array}$ & Vedmederja et al., 2007 & $\begin{array}{c}\text { Музей природы ХНУ, } \\
\text { Инв. № Г-1447, } 4 \text { экз.; № Г-1438, А.И. Зиненко }\end{array}$ \\
\hline 40 & $\begin{array}{c}2005 \\
12-15.06\end{array}$ & с. Ивановка, Луганская обл. & Zagorodnjuk, 2014 & - \\
\hline 41 & 2005 & $\begin{array}{l}\text { Зап. «Провальская степь», } \\
\text { Луганская обл. }\end{array}$ & Мороз, 2005 & - \\
\hline 42 & 2006 & $\begin{array}{l}\text { Окр. пос. Минеральное, } \\
\text { Донецкая обл. }\end{array}$ & $\begin{array}{c}\text { L.Y. Taranenko } \\
\text { (personal comment) }\end{array}$ & - \\
\hline 43 & $\begin{array}{l}2007 \\
\text { VIII }\end{array}$ & $\begin{array}{c}\text { Слияние р. Оскол и Сев. Донец, } 3 \text { км } \\
\text { от ст. Букино, Харьковская обл. }\end{array}$ & $\begin{array}{c}\text { A.S. Zvjagin } \\
\text { (personal comment) }\end{array}$ & - \\
\hline 44 & $\begin{array}{l}2008 \\
02.07\end{array}$ & Окр. с. Гончаровка, Луганская обл. & Zagorodnjuk, 2014 & - \\
\hline
\end{tabular}


Окончание табл.

\begin{tabular}{|c|c|c|c|c|}
\hline 1 & 2 & 3 & 4 & 5 \\
\hline 45 & $2009-2013$ & $\begin{array}{c}\text { Окр. сс. Фомовка и } \\
\text { Преображенное, Луганская обл. }\end{array}$ & Zagorodnjuk, 2014 & - \\
\hline 46 & $2009-2013$ & $\begin{array}{l}\text { Окр. с. Нижняя Дуванка, } \\
\text { Луганская обл. }\end{array}$ & Zagorodnjuk, 2014 & - \\
\hline 47 & 2010 & $\begin{array}{l}\text { Окр. с. Красный Октябрь, } \\
\text { Луганская обл. }\end{array}$ & Zagorodnjuk, 2014 & - \\
\hline 48 & $\begin{array}{l}2010 \\
14.05\end{array}$ & $\begin{array}{l}\text { Окр. с. Петровка, } \\
\text { Луганская обл. }\end{array}$ & Zagorodnjuk, 2014 & - \\
\hline 49 & 2006-2013 & Окр. г. Луганск, Луганская обл. & Zagorodnjuk, 2014 & - \\
\hline 50 & 2010 & Пгт. Дмитровка, Донецкая обл. & $\begin{array}{l}\text { L.Y. Taranenko } \\
\text { (personal comment) }\end{array}$ & - \\
\hline 51 & $\begin{array}{l}2011 \\
25.04\end{array}$ & Окр. г. Дебальцево, Донецкая обл & $\begin{array}{l}\text { M.O. Vysochin } \\
\text { (personal comment) }\end{array}$ & - \\
\hline 52 & $2003-2010$ & $\begin{array}{c}\text { Окр. пос. Бересток, } \\
\text { Константиновский р-н, } \\
\text { Донецкая обл., РЛП «Клебан-Бык» }\end{array}$ & our data & - \\
\hline 53 & $2003-2015$ & Окр. г. Дружковка, Донецкая обл. & our data & - \\
\hline 54 & $2003-2015$ & $\begin{array}{c}\text { Окр. с. Красноторка-Малотара- } \\
\text { новка, г. Краматорск, Донецкая обл. }\end{array}$ & our data & - \\
\hline 55 & $2003-2015$ & $\begin{array}{l}\text { Окр. пос. Белокузьминовка, } \\
\text { Донецкая обл. }\end{array}$ & our data & - \\
\hline 56 & $2003-2015$ & $\begin{array}{c}\text { Окр. сс. а) Беленькое, б) Вас. Пус- } \\
\text { тошь, в) Першомарьевка, г) Мали- } \\
\text { новка, д) Тихоновка, г. Краматорск, } \\
\text { Донецкая обл. } \\
\end{array}$ & our data & - \\
\hline 57 & - & $\begin{array}{c}\text { Покровский р-н, } \\
\text { Днепропетровская обл. }\end{array}$ & Bulakhov et al., 2007 & - \\
\hline
\end{tabular}

\section{Выводы}

В отсутствие более поздних наблюдений, находки узорчатого полоза в Одесской области и Крыму попрежнему остаются не подтвержденными. С одной стороны, возможна путаница, вызванная сложностью идентификации родственных E. sauromates и E. dione, которая подтверждается как свидетельствами известных герпетологов (Kessler, 1860; Nikol'skij, 1891; Strauch, 1873; Brauner, 1904), так и более поздними переопределениями (Shherbak, 1966; Kotenko, 2010). С другой стороны, идентификация по крайней мере двух экземпляров узорчатого полоза из числа спорных находок, хранящихся в настоящее время в коллекциях Парижского и СанктПетербургского музеев, не вызывает никаких сомнений (1916 г., Крым, Перекопский уезд, окр. дер. Кигач из ЗИН РАН; 1850 г., окр. Одессы из Парижского музея рисунки 1 и 2 соответственно). Следует отметить, что правильность идентификации не противоречит другому возможному объяснению - возможной ошибке этикетирования (Nikol'skij, 1916).

Также стоит считать неверным и указание находки узорчатого полоза с территории НПП «Святые горы» (Kotenko and Kondratenko, 2005; Kotenko and Kurjachij, 2008; Akimov, 2009). По сведениям Л.И. Тараненко (личное сообщение), указанный экземпляр пойман в окрестностях с. Кривая Лука (Краснолиманский р-н, Донецкая обл.) и был включен в список видов НПП ввиду близости точки находки к непосредственной территории национального парка. Каких-либо упоминаний и достоверно известных находок узорчатого полоза с указанной территории на данный момент нет.

В настоящее время все подтвержденные и современные места находок узорчатого полоза приурочены почти исключительно к территориям двух административных областей Украины - Донецкой и Луганской. Единственное наблюдение вида на территории Харьковской области нуждается в подтверждении. Что касается территории Днепропетровской области, то, учитывая близость основного ареала распространения, вероятность находки этого вида здесь достаточно велика.

\section{Благодарности}

Авторы выражают благодарность Олегу Кукушкину, Игорю Доронину, Ivan Ineich, Ирине Доценко, Валентине Орловой за оказанную помощь в доступе к коллекциям и литературе, а также Леониду Тараненко за предоставление ценных сведений. Работа выполнена при поддержке РФФИ, проект 15-35-50221 мол_нр.

\section{Библиографические ссылки}

Akimov, I.A. (ed), 2009. Chervona knyga Ukrai'ny. Tvarynnyj svit [The Red book of Ukraine. Fauna]. Globalkonsaltyng, Kyi'v (in Ukrainian).

Ananjeva, N.B., Borkin, L.J., Darevskij, I.S., Orlov, N.L., 1998. Zemnovodnye i presmykajushhiesja. Jenciklopedija prirody Rossii [Amphibians and reptiles. Encyclopedia of nature of Russia]. ABF, Moskva (in Russian).

Bannikov, A.G., Darevskij, I.S., Ishhenko, V.G., Rustamov, A.K., Shherbak, N.N., 1977. Opredelitel' zemnovodnyh i presmykajushhihsja fauny SSSR [Key to amphibians and reptiles of fauna of USSR]. Prosveshhenie, Moskva (in Russian).

Brauner, A., 1903. Predvaritel'noe soobshhenie o presmykajushhihsja i gadah Bessarabii, Hersonskoj gubernii, Kryma i severo-zapadnogo Kavkaza mezhdu Novorossijskom i Adlerom [Announcement about reptiles and snakes of Bessarabia, Kherson province, the Crimea and the northwest Caucasus from Novorossiysk city till Adler city]. Zap. Novoros. Obshh. Estestv. 25, 43-59 (in Russian). 
Brauner, A., 1904. Kratkij opredelitel' presmykajushhihsja i zemnovodnyh Kryma i stepnoj polosy Evropejskoj Rossii [Brief key to reptiles and amphibians of the Crimea and the steppe band of European part of Russia]. Odessa (in Russian).

Brauner, A., 1905. Predvaritel'noe soobshhenie o presmykajushhihsja i zemnovodnyh Kryma, Kubanskoj oblasti, Volyns'koj i Varshavskoj gubernij [Announcement about reptiles and amphibians of the Crimea, Kuban' region, Volyn' and Warsaw provinces]. Zap. Novoros. Obshh. Estestv. 28, 89-102 (in Russian).

Bulakhov, V.L., Gasso, V.Y., Pakhomov, O.Y., 2007. Biologichne riznomanittja Ukrainy. Dnipropetrovs'ka oblast'. Zemnovodni ta plazuni (Amphibia et Reptilia) [Biological diversity of Ukraine. Dnepropetrovsk region. Amphibians and reptiles (Amphibia et Reptilia)]. Dnipropetr. Univ. Press, Dnipropetrovs'k (in Ukrainian).

Cemsh, I.O., 1939. Do systematyky ta geografichnogo poshyrennja amfibij ta reptylij na Ukrainy [About systematics and geographic distribution of amphibians and reptiles in Ukraine]. T.G. Shevchenko Kyiv Derzh. Univ., Kyiv (in Ukrainian).

Docenko, I.B., 2003. Katalog kollekcij Zoologicheskogo muzeja NNPM NAN Ukrainy. Zmei [Catalogue of collections of the Zoological Museum of Naturel History, Ukrainian Academy of Sciences. Serprntes]. Zoomuzej NNPM NAN Ukrainy, Kiev (in Russian).

Duméril, A.M.C., Bibron, G., 1854. Erpétologie générale ou histoire naturelle complète des reptiles. De l'ordre des serpents ou des ophidiens [Common herpetology or the complete natural history of reptiles. In the order of reptiles or snakes]. Paris (in French).

Dunaev, E.A., Orlova, V.F., 2003. Raznoobrazie zmej (po materialam jekspozicii Zoologicheskogo muzeja MGU) [Diversity of snakes (after the works of the Zoological Museum of the Moscow State University)]. MGU, Moskva (in Russian).

Gromov, I.M. 1961. Iskopaemye verhnechetvertichnye gryzuny predgornogo Kryma [Fossil upperquaternary rodents of piedmont area of the Crimea]. AN SSSR, Moskva (in Russian).

Karmyshev, J.V., 2002. Plazuni pivdnja stepovoï zoni Ukrai'ny (Poshirennja, minlivist', sistematika ta osoblivosti biologii) [Reptiles of the South of steppe zone of Ukraine (distribution, variability, systematics and features of biology)]. Kiev (in Ukrainian).

Kessler, K.F., 1860. Puteshestvie, s zoologicheskoju cel'ju, k severnomu beregu Chernogo morja i v Krym, v 1858 godu [Journey with the zoological purpose to the Black sea's north shore and the Crimea in 1858]. Kiev (in Russian).

Kotenko, T.I., 2010. Zemnovodnye i presmykajushhiesja Kryma [Amphibians and reptiles of Crimea]. Nauch. Zap. Prir. Zapov. Mys Mart'jan 1, 171-224 (in Russian).

Kotenko, T.I., Kondratenko, A.V., 2005. O rasprostranenii uzorchatogo poloza, Elaphe dione (Reptilia, Colubridae) v Ukraine [About distribution of the Dione snake, Elaphe dione (Reptilia, Colubridae) in Ukraine]. Vestnik Zoologii 39(2), 46 (in Russian).

Kotenko, T.I., Kukushkin, O.V., 2003. Osobennosti rasprostranenija zmej na Krymskom poluostrove. Chast' 1 [Features of distribution of reptiles on the Crimean peninsula. Part 1]. Zmei Vostochnoj Evropy. Mater. Mezhdunar. Konf. 35-41 (in Russian).

Kotenko, T.I., Kurjachij, K.V., 2008. Znahidky u Donec'kij oblasti vydiv plazuniv, zaproponovanyh do vkljuchennja u tretje vydannja Chervonoi' knygy Ukrai'ny [Findings of reptiles in Donetsk region, suggested to enter in the $3 \mathrm{~d}$ edition of the Red book of Ukraine]. Znahidky Tvaryn Chervonoi' knygy Ukrai'ny 152-170 (in Ukrainian).

Kukushkin, O.V. Shaganov, V.V., 2007. Obzor gerpetofauny Opukskogo zapovednika: Vidovoj sostav, prostranstvennoe raspredelenie i rekomendacii po ohrane [Review of the fauna of the reptiles of the Opuck reserve: Species composition, spatial distribution and recommendations on protection]. Mater. IV Mezhdunar. Nauchn.-Prakt. Konf. Ch. 2 Zool. 72-80 (in Russian).

Kukushkin, O.V., 2013. Genezis gerpetofauny Kryma: Novoe videnie problemy [Genesis of the reptiles' fauna of the Crimea: A new vision of the problem]. Materialy mezhdunarodnoj nauchnoj konferencii, posvjashhennoj 100-letnemu jubileju so dnja rozhdenija Semena Ljudvigovicha Deljamure i 90-letiju so dnja rozhdenija Aleksandra Sergeevicha Skrjabina. Simferopol. 22-25 (in Russian).

Kukushkin, O.V., 2013. Novyj dannye po faune i sistematike zemnovodnyh i presmykajushhihsja Kryma [New data about fauna and systematics of amphibians and reptiles of the Crimea]. Materialy mezhdunarodnoj nauchnoj konferencii, posvjashhennoj 100-letnemu jubileju so dnja rozhdenija Semena Ljudvigovicha Deljamure i 90-letiju so dnja rozhdenija Aleksandra Sergeevicha Skrjabina. Simferopol. 21-22 (in Russian).

Kukushkin, O.V., Kotenko, T.I., 2003. Osobennosti rasprostranenija zmej na Krymskom poluostrove. Chast' 2 [Features of distribution of reptiles on the Crimean peninsula. Part 2]. Zmei Vostochnoj Evropy. Mater. Mezhdunar. Konf. 41-45 (in Russian).

Kurjachij, K.V., Tupikov, A.I., 2008. Novye dannye ob uzorchatom poloze (Elaphe dione Pallas, 1773) v Doneckoj oblasti [New data about the Dione snake (Elaphe dione Pallas, 1773) in Donetsk region]. Problemy Ekologii' ta Ohorony Pryrody Tehnogennogo Regionu 8, 104-109 (in Russian).

Nikol'skij, A.M., 1891. Pozvonochnye zhivotnye Kryma [Vertebrate animals of the Crimea]. Tipografija Imp. Akad. Nauk, Sankt-Peterburg (in Russian).

Nikol'skij, A.M., 1905. Presmykajushhiesja i zemnovodnye Rossijskoj imperii. Herpetologia Rossica [Reptiles and amphibians of the Russian Empire. Herpetologia Rossica]. Zap. Akad. Nauk. 17(1) (in Russian).

Nikol'skij, A.M., 1907. Opredelitel' presmykajushhihsja i zemnovodnyh Rossijskoj imperii [Key to reptiles and amphibians of the Russian Empire]. Har'kov (in Russian).

Nikol'skij, A.M., 1916. Fauna Rossii i sopredel'nyh stran. Presmykajushhiesja. T. 2. Ophidia [Fauna of Russia and neighbouring countries. Reptiles]. Petrograd (in Russian).

Pakhomov, O.Y., Gasso, V.Y., Goloborodko, K.K., Poljakov, M.V., Grycan, Y.I., Bulakhov, V.L., Brygadyrenko, V.V., Kljuchko, Z.F., Mezhzherin, S.V., Novicky, R.O., Pysanec, Y.M., Pljushh, I.G., Ponomarenko, O.L., Puchkov, O.V., Radchenko, V.G., 2011. Chervona knyga Dnipropetrovskoi oblasti. Tvarynnyj svit [The red book of Dnipropetrovsk region. Animals]. New Print, Dnipropetrovsk (in Ukrainian).

Pashhenko, J.I., 1954. O rasprostranenii uzorchatogo poloza (Elaphe dione Pall.) na Ukraine [About the distribution of the Dione snake (Elaphe dione Pall.) in Ukraine]. Naukovi Zapysky KDU 12, 136 (in Russian).

Ratnikov, V.J., 2009. Iskopaemye ostatki sovremennyh vidov zemnovodnyh i cheshujchatyh presmykajushhihsja kak material dlja izuchenija istorii ih arealov [Fossil remains of the present species of amphibians and scaled reptiles as the data for examination of the history of its areals]. Trudy NauchnoIssledovatel'skogo Instituta Geologii Voronezhskogo Gosudarstvennogo Universiteta 59 (in Russian).

Reva, M.L., Taranenko, L.I., Molodan, G.V., Panchenko, A.B., Rjazanceva, A.E., Jaroshenko, N.N., 1989. Stranicy krasnoj knigi. Nauchno-populjarnye ocherki [Pages of the Red book. Popular science essays]. Donbass, Doneck (in Russian).

Shherbak, N.N. (ed), 1989. Rukovodstvo po izucheniju zemnovodnyh i presmykajushhihsja [Amphibians and reptiles examination guide]. Kiev (in Russian). 
Shherbak, N.N., 1966. Zemnovodnye i presmykajushhiesja Kryma. Herpetologia Taurica [Amphibians and reptiles of the Crimea. Herpetologia Taurica]. Naukova Dumka, Kiev (in Russian).

Strauch, A., 1873. Die Schlangen des Russischen Reichs, in systematischer und zoogeographischer Beziehung [Snakes of the Russian Empire, in the matter of systematics and zoogeographics]. Mémoires Acad. Imp. Sci., St. Pétersbourg. 21(4), 82-92 (in German).

Sukhow, G.F., 1927. Ueber die Verbreitung von Elaphe dione (Pall.) in Ukraine [About the distribution of the Elaphe dione (Pall.) in Ukraine]. Zbirn. Prac' Zoologichnogo Muzeju, Kiev. 7(1), 59-60 (in German).

Tarashchuk, V.I., 1956. Do poshyrennja vizerunkovogo poloza [About the distribution of the Dione snake]. Zbirn. Prac' Zoologichnogo Muzeju, Kiev. 27, 173-174 (in Ukrainian).

Tarashchuk, V.I., 1959. Zemnovodnye i presmykajushhiesja [Amphibians and reptiles]. AN USSR, Kiev. 7 (in Russian).

Terent'ev, P.V., Chernov, S.A. 1965. Key to amphibians and reptiles. 3rd edition. Translated from Russian. Israel Program for Scientific Translations Ltd., Jerusalem.

Terent'ev, P.V., Chernov, S.A., 1936. Kratkij opredelitel' zemnovodnyh i presmykajushhihsja SSSR [Brief key to amphibians and reptiles of the USSR]. Gosudarstvennoe UchebnoPedagogicheskoe Izdatel'stvo, Moskva (in Russian).

Terent'ev, P.V., Chernov, S.A., 1949. Opredelitel' zemnovodnyh i presmykajushhihsja [Key to amphibians and reptiles]. Sov. Nauka, Moskva (in Russian).

Vedmederja, V.I., Zinenko, A.I., Goncharenko, L.A., 2007. Katalog kollekcij Muzeja prirody Har'kovskogo nacional'nogo universiteta im. V.N. Karazina. Zmei (Reptilia: Ser- pentes) [Catalogue of collections of the Museum of Nature at V.N. Karazin Kharkiv National University. Snakes (Reptilia: Serpentes)]. Har'kov (in Russian).

Vlasenko, V.N., Taranenko, L.I., 2002. K rasprostraneniju uzorchatogo poloza (Elaphe dione) na territorii Doneckoj oblasti [About the distribution of the Dione snake (Elaphe dione) on the territory of Donetsk region]. I Mizhnar. nauk. konf. aspirantiv ta studentiv «Ohorona navkolyshn'ogo pryrodnogo seredovyshha ta racional'ne vykorystannja pryrodnyh resursiv», Donec'k. 2, 86-87 (in Russian).

Vlasenko, V.N., Taranenko, L.I., 2003. Uzorchatyj poloz (Elaphe dione) na territorii Doneckoj oblasti [Dione snake (Elaphe dione) on the territory of Donetsk region]. II Mizhnar. nauk. konf. aspirantiv ta studentiv «Ohorona navkolyshn'ogo pryrodnogo seredovyshha ta racional'ne vykorystannja pryrodnyh resursiv», Donec'k. 2, 37-38 (in Russian).

Zagorodnjuk, I., Korobchenko, M., 2014. Rarytetna fauna Luganshhyny: Hrebetni pershochergovoi' uvagy [Rare fauna of Lugansk region: Vertebrate animals of primary importance]. Shyko, Lugans'k (in Ukrainian).

Zagorodnjuk, I.V., Zai'ka, S., 2009. Novi znahidky ridkisnyh vydiv zmij (Reptilia, Serppentes) na Luganshhyni [New findings of rare species of snakes (Reptilia, Serppentes) in Lugansk region]. Vestn. Zool. 43(3), 266 (in Ukrainian).

Zaika, S., 2008. Poloz uzorchatyj, Elaphe dione (Colubridae), v doline rechki Krasnja na Luganshhine (Vostochnaja Ukraina) [Dione snake, Elaphe dione (Colubridae), in the Krasnaya River Valley in Lugansk region (Eastern Ukraine)]. Vestn. Zool. 42(3), 248 (in Russian).

Надійшла до редколегї 29.06.2015 